\title{
Comments on Brugger and others (2018) 'A quantitative comparison of microfossil extraction methods from ice cores'
}

\author{
DANIELA FESTI, (1) WERNER KOFLER, KLAUS OEGGL \\ Department of Botany, University of Innsbruck, Sternwartestraße 15, A-6020 Innsbruck, Austria \\ Correspondence: Daniela Festi <Daniela.Festi@uibk.ac.at>
}

\begin{abstract}
In our comments, we re-evaluate Brugger and others (2018) Lycopodium/Eucalyptus double marker approach, based on the fact that previous evidence already demonstrated that the batch of Eucalyptus tablets used by Brugger and others (2018) is not suitable for quantitative comparisons as they are characterized by inconsistent pollen concentration. We present clear evidence that the Eucalyptus tablets do feature inaccurate pollen concentrations, and are therefore improper for all quantitative comparisons of microfossil extraction methods. Consequently, the results of the quantitative and qualitative assessment of different pollen extraction methods from ice samples compiled by Brugger and others (2018) are highly questionable due to the use of faulty marker tablets.
\end{abstract}

KEYWORDS: ice biology, ice/atmosphere interactions, polar biology

\section{INTRODUCTION}

In their paper 'A quantitative comparison of microfossil extraction methods from ice cores', Brugger and others (2018) present a comparative evaluation of six pollen extraction protocols from ice samples, by assessing the effects of three types of water reduction procedures: (i) evaporation (Liu and others, 1998, 2005, 2007; Yang and others, 2008; Brugger and others, 2018), (ii) filtration (Short and Holdsworth, 1985) and (iii) centrifugation (Eichler and others, 2011; Festi and others, 2015). To quantify the differences among protocols, the authors applied a 'double marker approach', which consists of adding a known amount of Lycopodium marker spores at the beginning of the laboratory process, and a second marker (Eucalyptus pollen) at its completion. By doing so, the amount of Lycopodium loss during the procedure can be quantified based on the resulting Lycopodium/Eucalyptus ratio. In principle, the estimated loss in Lycopodium should reflect the eventual reduction in the quantity of microfossils originally contained in the sample, hence enabling an estimation of the total microfossil loss occurred during the extraction process. Furthermore, Brugger and others (2018) calculated for each extraction method the coefficient of determination $\left(R^{2}\right)$ based on the Lycopodium and Eucalyptus values obtained after sample treatment, and used it as a measure for loss variability. Based upon these Lycopodium-Eucalyptus statistics, i.e. Lycopodium/Eucalyptus ratios and derived Lycopodium loss percentages and $R^{2}$, a quality ranking of the extraction methods was compiled by the authors.

Here, we re-evaluate the Brugger and others (2018) approach, based on the fact that already O'Rourke (1986) demonstrated that Eucalyptus tablets are unreliable, because of deficient pollen content. Following up on O'Rouke (1986) results, we present evidence that the Eucalyptus tablets do feature inaccurate pollen concentrations, and are therefore suboptimal for all quantitative comparisons of microfossil extraction methods.

\section{METHODS}

First of all, we tested the reliability of the Eucalyptus and Lycopodium marker tablets used by Brugger and others (2018). The Lycopodium tablets (batch \#3862) were purchased in October 2015 from the Lund University, Department of Geology, Lund, Sweden, while the Eucalyptus tablets (batch \#106720) were acquired in 1980/81 from the Department of Quaternary Geology, University of Lund, Lund, Sweden (S. Bortenschlager, pers. comm.). Both Lycopodium and Eucalyptus batches are exactly the same that Brugger and others (2018) used in their comparative analyses.

To test the reliability we mixed one Lycopodium tablet and one Eucalyptus tablet in a sample tube. A total of 20 samples of such Lycopodium-Eucalyptus pairs were dissolved in $10 \% \mathrm{HCl}$, following standard procedures (Moore and others, 1991). No washing with $\mathrm{H}_{2} \mathrm{O}$ and no centrifugation/decantation were done to avoid any loss of markers. The suspensions were then mounted on microscopic slides, and at least 1000 grains (Lycopodium + Eucalyptus) were counted at 400x magnification (Olympus BX50). The results were compared to the expected Lycopodium/Eucalyptus ratio (0.66-0.78) (Brugger and others 2018). The expected range of the ratio is based on the mean values and std dev. given for Lycopodium batch \#3862 $(9666 \pm 671)$ and Eucalyptus batch \#106720 (13500 \pm 210$)$.

\section{RESULTS AND DISCUSSION}

Contrary to Brugger and others (2018), our analysis revealed that, based on a total pollen sum of 1000 marker grains, the Lycopodium/Eucalyptus ratio varied between 0.52 and 0.81 . Specifically, in $40 \%$ of the samples (eight out of 20), the Lycopodium/Eucalyptus ratio was outside the expected ratio of 0.66 to 0.78 (Fig. 1). This firmly indicates that at least one of the two marker types cannot unequivocally be used for quantitative studies.

The deviations from the expected ratio are caused by inconsistent pollen content in the Eucalyptus tablets (batch $\# 106720$ ), since Lycopodium tablets (batch \#3862) are standardized and quality checked (http://www.geology.lu.se/services/pollen-tablets). It has been known for some time (O'Rourke, 1986) that Eucalyptus tablets (batch \#106720), as used by Brugger and others (2018), have deficiencies. O'Rourke (1986) studied atmospheric pollen content in the years 1981 and 1982 using sequentially collected Tauber traps located at Tumamoc Hill (Tucson, Arizona, USA), and 


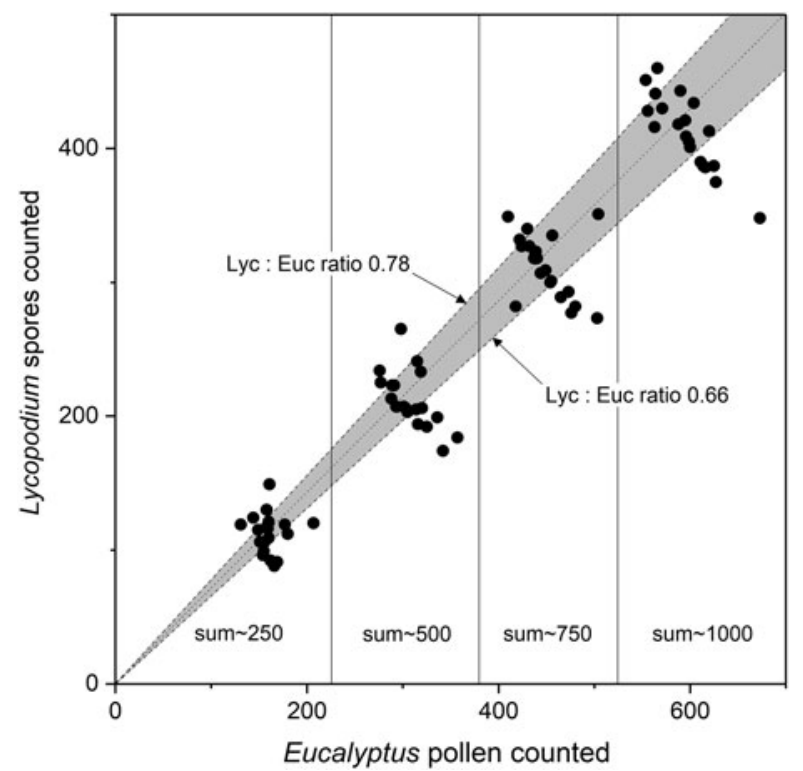

Fig. 1. Marker ratio of Lycopodium to Eucalyptus. Average (ideal) marker relationship (dotted line) based on mean tablet concentrations and expected confidence intervals for marker tablet uncertainties (grey area) based on the average and std dev. of tablet concentrations of Lycopodium batch \#3862 (9666 \pm 671$)$ and Eucalyptus batch $\# 106720(13500 \pm 210)$ are shown. Expected upper and lower Lycopodium/Eucalyptus (Lyc:Euc) ratios (dashed lines). Measured Lycopodium/Eucalyptus relationships (black dots, this study) showing stepwise relation at different marker sums (Lycopodium + Eucalyptus $=250, \quad 500,750$ and 1000).

found strong discrepancies in the annual pollen accumulation rates, i.e. $\sim 24.000$ pollen $\mathrm{cm}^{-2}$ in 1981 and $\sim 4100$ pollen $\mathrm{cm}^{-2}$ in 1982 . The author stated that a pollen accumulation rate of $3.000-4.000$ pollen $\mathrm{cm}^{-2} \mathrm{a}^{-1}$, similar to the 1982 value, is accurate for Tumamoc Hill, whereas the 1981 value is an order of magnitude higher (O'Rourke, 1986 , p. 108). According to the author, the discrepancy in the pollen accumulation rates is due to the use of different batches of tracers. In this regard O'Rourke (1986, p. 108) stated: 'The 1981 samples were calibrated using Eucalyptus (batch \#106720), whereas the 1982 samples were calibrated using Lycopodium (batch \#201890); both products were purchased from Berglund and Perrson, Department of Quaternary Geology, University of Lund, Lund, Sweden. Robert Thompson used both tracers in 20 samples from the Ruby Marshes and found that Lycopodium:Eucalyptus ratios varied from 0.3 to 1.8. He attributed the differences to inconsistent pollen concentration in the Eucalyptus tablets (Thompson pers. comm.). Eucalyptus tablets were calibrated using Jørgensen's (1967) technique. Jørgensen (1967, p. 439) described the reliability of his technique as follows: 'Hard-earned experience has taught me that reliable results depend on clean and careful work ....' Lycopodium tablets were calibrated using an electronic particle counter (Stockmarr, 1973), and these results appear more reliable'.

We analyzed 20 Lycopodium-Eucalyptus samples, rather than the ten analyzed by Brugger and others (2018), and our results are more consistent with those of O'Rourke (1986). Our findings suggest that the results of Brugger and others (2018) are likely to have been affected by the faulty Eucalyptus tablets (batch \#106720). In particular, it is likely that: (i) Lycopodium/Eucalyptus ratios and derived
Lycopodium loss percentages are incorrect, (ii) Lycopodium-Eucalyptus derived $R^{2}$ values and (iii) TukeyKramer post-hoc test for the marker ratios are incorrect. Therefore, the conclusions drawn by Brugger and others (2018) concerning the quality ranking of the six tested ice pollen extraction methods, which are based on erroneous Lycopodium/Eucalyptus statistics, need to be corrected using high-quality markers.

A second issue discussed by Brugger and others (2018) deals with the finding that samples obtained by multiple centrifugation and decantation (i.e. Festi- and Eichler protocols) show statistically significantly lower values in vesiculate pollen percentages compared with samples obtained by evaporation or filtration (i.e. Brugger-, Liu-, Short- and Yang method; see ANOVA Fig. 3 in Brugger and others, 2018). According to Brugger and others (2018) and in our experience, vesiculate pollen loss potentially increases with the number of centrifugation steps. We do not disagree on this fact, but we are surprised that Brugger and others (2018) chose to modify the extraction protocol by Festi and others (2015) in a substantial way. Festi's original protocol was modified by Brugger and others (2018) in at least two crucial points: (i) the number of centrifugation steps and (ii) type and size of centrifugation tubes used. The modification of Festi's method inevitably led to a higher loss of vesiculate pollen for the following reasons:

\subsection{Ad (i) number of centrifugation steps}

The extraction protocol used by Festi and others (2015) was developed for ice samples of very small volume in the frame of the project 'PAMOGIS-Pollen analyses of the Mt. Ortles ice samples', where a high number ( 1850) of very small ice samples from the Alto dell' Ortles glacier ice core were processed for pollen analysis. As the average volume of the Ortles ice samples is $\sim 30 \mathrm{~mL}$, at the beginning of the treatment, only one single centrifugation step was necessary to reduce the ice water to a $12 \mathrm{~mL}$ test tube with the original Festi method.

By changing our protocol, Brugger and others (2018) performed ten additional centrifugation/decantation steps to reduce the volume $(370-400 \mathrm{~mL})$. As the number of centrifugation steps is crucial for microfossil losses (Brugger and others 2018) this modification of the Festi protocol inevitably leads to a higher loss of vesiculate pollen.

\subsection{Ad (ii) type and size of centrifugation tubes used}

We operate exclusively with special pointed $12 \mathrm{~mL}$ sample tubes made of glass. The pointed ends of these tubes are characterized by an acute angle of $30^{\circ}$, resulting in strong capillary forces at the bottom of the tube. Consequently during centrifugation, tiny stable pellets (pollen, dust, micro-charcoal, etc.) sediment at the bottom. In addition, capillary forces ensure that a stable liquid column (supernatant) persists in the tube tip during decantation, further preventing a larger loss of the settled material.

Brugger and others (2018) conducted our method in different $50 \mathrm{~mL}$ tubes with considerable more (ten) centrifugation/decantation steps. In our experience, all available types of the $50 \mathrm{~mL}$ centrifugation tubes are unsuitable for the centrifugation of suspensions with low pollen concentration, such as melted ice, because the morphology of their bottom part facilitates the complete removal of the supernatant, which in turn increases the probability for pollen loss during decantation. This negative 
effect is clearly amplified when treating samples characterized by extremely low pollen/dust/particle content.

\section{CONCLUSION}

Our results confirm O'Rourke's (1986) findings that Eucalyptus tablets batch \#106720 show inconsistent pollen concentrations. In fact, in $40 \%$ of the Lycopodium/ Eucalyptus samples analyzed, there is a pronounced deviation from the expected ratio, which can lead to distinctly faulty results. We strongly recommend that, if laboratories have these tablets batch still in stock, they should no longer be used for statistical purposes in pollen analysis. Consequently, the results of the quantitative and qualitative assessment of different pollen extraction methods from ice samples reported by Brugger and others (2018) are questionable because of the use of faulty marker tablets and substantial modifications of the Festi extraction protocol.

\section{REFERENCES}

Brugger SO and 7 others (2018) A quantitative comparison of microfossil extraction methods from ice cores. J. Glaciol., 64(245), 432-442 (doi: 10.1017/jog.2018.31)

Eichler A and 5 others (2011) An ice-core based history of Siberian forest fi res since AD 1250. Quat. Sci. Rev., 30(9-10), 1027-1034 (doi: 10.1016/j.quascirev.2011.02.007)

Festi D and 6 others (2015) A novel pollen-based method to detect seasonality in ice cores: a case study from the Ortles glacier,
South Tyrol, Italy. J. Glaciol., 61, 815-824 (doi: 10.3189/ 2015JoG14J236)

Jørgensen S (1967) A method of absolute pollen counting. New Phytol., 66, 489-493

Liu KB, Yao Z and Thompson LG (1998) A pollen record of Holocene climatic changes from the Dunde ice cap, QinghaiTibetan Plateau. Geology, 26(2), 135-138 (doi: 10.1130/00917613(1998)026<0135:APROHC > 2.3.CO;2)

Liu KB, Reese CA and Thompson LG (2005) Ice-core pollen record of climatic changes in the central Andes during the last $400 \mathrm{yr}$. Quat. Res., 64(2), 272-278 (doi: 10.1016/j.yqres.2005.06.001)

Liu KB, Reese CA and Thompson LG (2007) A potential pollen proxy for ENSO derived from the Sajama ice core. Geophys. Res. Let., 34(9), L09504 (doi: 10.1029/2006GL029018)

Moore PD, Webb JA and Collison ME (1991) Pollen analysis. Blackwell Scientific Publications, Oxford

O'Rourke MK (1986) The implications of atmospheric pollen rain on fossil pollen profiles in the arid Southwest (Aerobiology, Palaeobotany, Taphonomy, Preservation). (Ph.D. Dissertation, Univ. of Arizona, Tucson)

Short SK and Holdsworth G (1985) Pollen, oxygen isotope content and seasonally in an ice core from the Penny Ice Cap, Baffin Island. Arctic, 38(3), 214-218 (doi: 10.14430/arctic2136)

Stockmarr J (1973) Determination of spore concentration with an electronic particle counter. Danmarks Geologiske Undersoegelse Arbog 87-89

Yang B and 5 others (2008) Summer temperature reconstruction on the central Tibetan Plateau during 1860-2002 derived from annually resolved ice core pollen. J. Geophys. Res. Atmos., 113(D24), D24102 (doi: 10.1029/2008JD010142) 